\title{
Foraging activity pattern and herbivory rates of the grass-cutting ant Atta capiguara
}

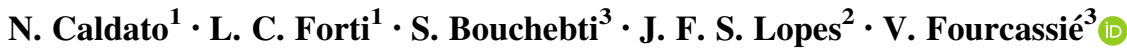

Received: 20 August 2015/Revised: 8 March 2016/ Accepted: 9 March 2016/Published online: 25 March 2016

(C) International Union for the Study of Social Insects (IUSSI) 2016

\begin{abstract}
The objective of this study was to investigate the seasonal change in the pattern of foraging activity in the leaf-cutting ant Atta capiguara and to provide an estimate of the annual herbivory rate of its colonies. We surveyed at least once a month during 12 months, the foraging activity of two colonies located in a pasture of central Brazil. Each survey consisted in counting the number of ants exiting and returning (laden or unladen) to their nests during $10 \mathrm{~min}$ every hour during $24 \mathrm{~h}$. The air temperature and relative humidity were noted at the beginning of each survey. Independent of the season, the colonies presented two peaks of foraging activity, one small peak at the beginning of the day and another peak at the end of the day. During the dry season, the diurnal activity ceased almost completely between 10:00 and 16:00. The proportion of ants returning to the nest laden with a leaf fragment was also lower than during the humid season. Activity rhythm depended significantly on both air temperature and humidity: foraging activity peaked when the temperature was around $25^{\circ} \mathrm{C}$ and relative humidity around $66 \%$. Based on the statistical
\end{abstract}

Electronic supplementary material The online version of this article (doi:10.1007/s00040-016-0479-x) contains supplementary material, which is available to authorized users.

V. Fourcassié

vincent.fourcassie@univ-tlse3.fr

1 Departamento de Proteção Vegetal, Faculdade de Ciências Agronômicas, Universidade Estadual Paulista, P.O. Box 237, 18610-307 Botucatu, SP, Brazil

2 Instituto de Ciências Biológicas, Universidade Federal de Juiz de Fora, Campus Universitario de Martelos, 36036-330 Juiz de Fora, MG, Brazil

3 Centre de Recherches sur la Cognition Animale, Centre de Biologie Intégrative, Université de Toulouse, CNRS, UPS, 118 route de Narbonne, 31062 Toulouse Cedex 9, France model used to describe the activity rhythm, we estimated that over a period of 1 year, the total dry biomass of vegetation collected by the two colonies studied was, respectively, $25.16 \mathrm{~kg}$ for the bigger nest, and $11.69 \mathrm{~kg}$ for the smaller one, or an equivalent of $104.83-\mathrm{kg}$ and $48.71-\mathrm{kg}$ fresh biomass, respectively.

Keywords Abiotic factors · Activity rhythm · Brazil · Foraging $\cdot$ Herbivory rate $\cdot$ Leaf-cutting ants

\section{Introduction}

Leaf-cutting ants (hereafter LCA) of the genus Atta are considered as the dominant herbivore in neotropical ecosystems and one of the major pest for agriculture in South America (Della Lucia et al. 2014), particularly in Brazil where they present a high species diversity. In fact, of the 15 different species of Atta known in Neotropical America, 9 occur in Brazil and 5 are recognized as economically important because of their damages to agricultural crops (Forti and Boaretto 1997; Delabie et al. 2011). These ants are generally characterized by a rhythmic activity pattern, which can be the same during several weeks or months but which can also change rather abruptly within a few days. Hence, workers that have foraged for months during the diurnal part of the nycthemere can begin foraging at night from 1 day to the other (Lewis et al. 1974a; CedenõLeon 1984). As in other ant species (Hölldobler and Wilson 1990), meteorological conditions are considered as essential in determining the pattern of foraging activity in LCA, and air temperature and relative humidity are generally reported to be the main factors determining their activity rhythm (Amante 1967a; Hölldobler and Wilson 2010). The short review of the literature on activity rhythm in Atta that 
follows, however, shows that activity rhythm in these species can be extremely variable, and that the role of these factors is not so clearly delineated.

In tropical climates, where the temperature is relatively constant throughout the year and where seasonality is defined mainly by an alternance between a dry season and a humid season, foraging activity does not seem to be characterized by marked regular fluctuations. For example, Farji-Brener (1993) reports an absence of synchronization in the activity rhythm of eight nests of A. laevigata located in a tropical savannah in Venezuela, suggesting that in tropical climates, the activity pattern of LCA is essentially regulated by factors intrinsic to the colonies. An absence of synchronization between neighboring nests in tropical forests has also been reported by Lewis et al. (1974b) and Wetterer (1990) for A. cephalotes and by Wirth et al. (2003) for A. colombica colonies, although A. cephalotes was found to be predominantly nocturnal and A. colombica essentially diurnal. Rockwood (1975) showed, however, that the activity rhythm of these two species varies between seasons: in both A. cephalotes and A. colombica, foraging is essentially nocturnal during the dry season, thus allowing to avoid the high diurnal temperatures, whereas it is essentially diurnal during the humid season. The same pattern of seasonal activity was observed by Fowler and Robinson (1979) for A. sexdens inhabiting subtropical Paraguay. In this species, a seasonal variation was noted not only in the activity pattern, but also in the length of the foraging trails and, consequently, in the extension of the foraging area of the colonies: during the months characterized by low mean temperatures, the foraging trails are short but numerous, while during the warmer months, there are less numerous but longer. Moreover, in all species of Atta, the amount of diurnal and nocturnal activity can vary greatly from one day to the other according to the amount of precipitation. Finally, in temperate climates, the activity pattern of LCA is clearly dependent on the variation of temperature accompanying the alternance of seasons: A. mexicana, for example, is diurnal in winter and spring and shift to a nocturnal activity in summer (Mintzer 1979).

Here, we present a study investigating the seasonal change in daily activity pattern in the LCA A. capiguara. Contrary to the species cited above that collect exclusively dicotyledons, or both monocotyledons and dicotyledons, this species collects exclusively monocotyledons, i.e., grass (Fowler et al. 1986). Hence, its economic importance in pastures and sugar cane plantations in Brazil (Fowler et al. 1990). We surveyed during 1 year at least once a month throughout $24 \mathrm{~h}$ the foraging activity of two colonies of $A$. capiguara located in a pasture of southeastern Brazil. This allowed us to characterize the activity rhythm of this species and to investigate to what extent it depends on air temperature and relative humidity. Based on the statistical model used to explain the rhythm, we then estimate the annual biomass of dry vegetation collected by the two colonies studied. Quantitative assessments of biomass consumption by the species of LCA found in savannahs and pastures in South America are indeed relatively scarce in the literature compared with the species of LCA found in tropical forests (see review in Lugo et al. 1973; Fowler et al. 1990; Herz et al. 2007), or are often very approximate (Fowler et al. 1986, but see Costa et al. 2008 for a more precise assessment of plant biomass consumption by A. laevigata in the Brazilian cerrado). Yet, these assessments are indispensable to understand the participation of LCA in the flow of energy and matter in tropical savannahs or pastures. One of the simple and most widespread methods used to assess biomass consumption in LCA is the method based on the measure of foraging activity, i.e., on the counts of the leaf fragments transported to the nest by foraging workers. Fowler et al. (1990) discussed the pro and cons of this method, but one of the major problems we identified with the use this method in the literature is that it extrapolates the biomass consumption over 12 months from the mean daily consumption calculated on a few days surveyed during this period, without considering the fact that the foraging activity in LCA depends heavily on abiotic factors. Here, we used our activity data, coupled with the recordings or air temperature and humidity, to build a statistical model that provides a more reliable assessment of the annual biomass collected by an LCA species in a cultivated pasture. This method also allows to give a confidence interval for the value of the prediction made.

\section{Materials and methods}

\section{Study location}

We worked on two colonies of A. capiguara located on a pasture adjacent to the campus of the State University of São Paulo, Botucatu, Brazil (22 $50^{\prime} 46^{\prime \prime} \mathrm{S}, 48^{\circ} 26^{\prime} 02^{\prime \prime} \mathrm{W}$ ) and grazed by cattle on a regular basis during the survey. Brachiaria spp. and Paspalum spp. were the dominant species of grass in the pasture. The size of the colonies, assessed by the area of loose soil over the underground nests at the start of the observation period, was $34.31 \mathrm{~m}^{2}$ for Nest 1 and $8.40 \mathrm{~m}^{2}$ for Nest 2 .

\section{Data collection}

The foraging activity of each colony was assessed during 1 year, approximately every 15 days, from July 15, 2011 to June 26, 2012, covering the whole dry season (which extends from July to October in Central Brazil) and the whole humid season (from November to June). There were 
eight activity censuses in the dry season and 14 activity censuses in the humid season. For each colony, the number of ants crossing an imaginary line across two active foraging trails at $2 \mathrm{~m}$ from their nest end and traveling either toward the end of the trail or in the nest direction (distinguishing between the workers that carried or not a leaf fragment) was counted during $10 \mathrm{~min}$ at the beginning of every hour during 24 consecutive hours. To investigate the effect of abiotic factors on activity rhythm, the temperature and relative humidity of the air were noted every hour, at the beginning of the recording session, by reading the values indicated by a Testo $175 \mathrm{H} 1$ data logger installed close to the point of traffic measurement. The temperature probe of the data logger was placed at $5 \mathrm{~cm}$ above the foraging trails.

\section{Data analysis}

Foraging activity rhythm was assessed by the total number of ants counted on the trails during a recording session, i.e., the sum of outbound and inbound ants. For each day of survey, we then calculated for each hour the mean number of ants per minute traveling over the two trails of each nest studied. These values were rounded to the nearest integer to build a database on which we fitted our statistical models.

To investigate the effect of time of day, air temperature (continuous variable), relative humidity (continuous variable), season (two-level categorical variable: dry and humid), nest (two-level categorical variable), and the interaction between time of day and season on foraging activity, we used a generalized linear model with a quasiPoisson residual distribution error to correct for overdispersion (Zuur et al. 2009). To consider the autocorrelation due to the circadian rhythm, the daily cycle was modeled by introducing as auxiliary independent variables $H_{\mathrm{cos}}=$ $\cos (2 \pi \quad$ Hour $/ 24)$ and $H_{\text {sin }}=\sin (2 \pi \quad$ Hour $/ 24)$, as implemented in van Oudenhove et al. (2011). Temperature and humidity were introduced in the model as second-degree polynomials. To minimize multicollinearity effects, these two variables were centered on their means in the statistical model.

To investigate the variation in foraging efficiency, i.e., the proportion of ants returning to the nest loaded with a leaf fragment, we fitted a generalized linear model with a quasibinomial residual distribution error to correct for overdispersion (Zuur et al. 2009). The effects of time ( $H_{\mathrm{cos}}$ and $H_{\mathrm{sin}}$ variables), air temperature, relative humidity, season, studied nest, and the interaction between time of day and season were entered as explanatory variables.

To assess the biomass of vegetation collected by ants over 1 year, we used a database obtained from the meteorological station of the Soil and Environmental Resource Department of the UNESP-Botucatu. This database gives the air temperature and relative humidity for each hour between November 1, 2011 and October 31, 2012. From our database of ant activity, we first calculated for each hour of each day of recording the mean over the two trails of each nest of the number of ants per minute returning with a fragment of vegetation. We then used a generalized linear model with a quasi-Poisson residual distribution error to model the effect of time of day, air temperature, and relative humidity on the number of laden ants returning to each nest per minute. As for the study of activity rhythm, temperature and humidity were entered in the model as second-degree polynomials, and the two auxiliary variables $H_{\sin }$ and $H_{\text {cos }}$ were used to model the circadian rhythm. We then used the equation of this model and the database of the UNESP meteorological station to predict the number of ants returning to the nest with a leaf fragment for each hour of each day between November 1, 2011 and October 30, 2012. To assess the dry biomass collected by ants in $1 \mathrm{~h}$, the number of laden ants was multiplied by the average dry weight of a leaf fragment (mean $\pm \mathrm{SD}=2.89 \pm 1.53 \mathrm{mg}$; $N=200$ ). A $95 \%$ confidence interval was calculated from the product of the SE of the model estimates by 1.96 . Finally, we used a database of the number of active trails recorded for each of the two nests studied at interval of about 15 days between November 10, 2011 and October 31, 2012 to calculate the total amount of dry biomass collected by the two studied colonies over 1 year (minus the 10 days at the beginning of October). We considered that all trails remained active between two consecutive nest surveys.

For all statistical models, we started with a full model and used a stepwise backward simplification procedure (based on the comparison of the scaled deviance of successive models with an $F$ test) to remove the non-significant effect until obtaining the most parsimonious model. To estimate model fit, a pseudo- $R^{2}$ was calculated using the deviances of the final model as compared with the null model (PearceDuvet et al. 2011). All data analysis and statistical tests were conducted and graphics generated with R 2.13.1 (R Development Core Team 2011).

\section{Results}

\section{Activity rhythm}

Figure 1 shows the daily variation of air temperature and relative humidity and Fig. 2 that of the foraging activity for the two studied nests during the dry and humid seasons, along with the predictions of the statistical model. Overall, the foraging activity was significantly higher for Nest 1 (Fig. 2a) than for Nest 2 (Fig. 2b) and depended significantly on the time of day, temperature, humidity and season, as well as on the interaction between time of day and season (Table 1). The model fitted reasonably well the observed 


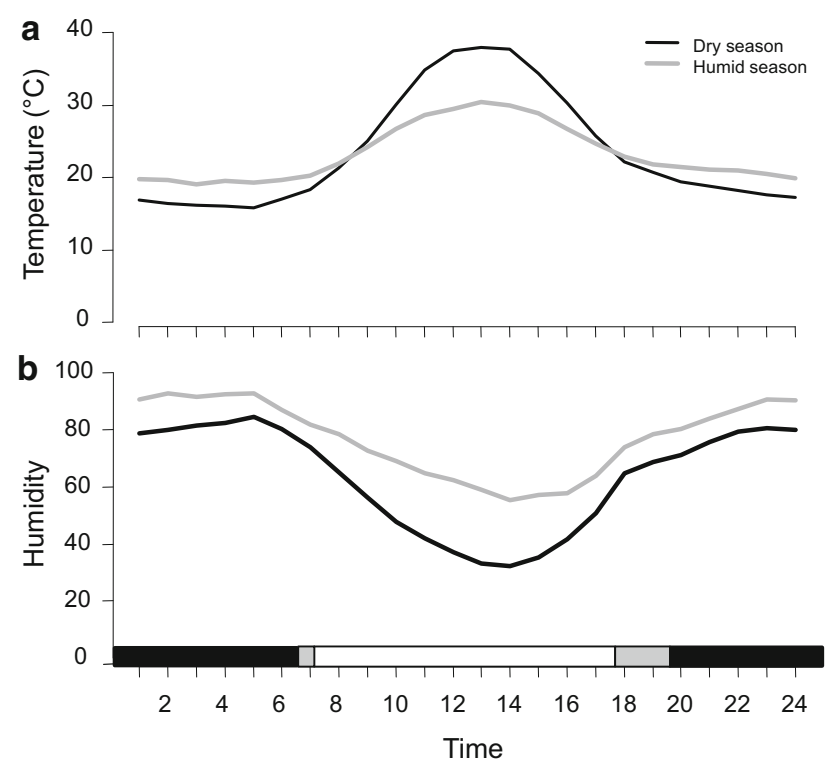

Fig. 1 Mean daily variation of $\mathbf{a}$ air temperature and $\mathbf{b}$ relative humidity during the dry (black lines) and humid season (gray lines) throughout the studied period. The bar over the $x$-axis shows the time corresponding to the diurnal part (white rectangle) and the nocturnal part (black rectangle) of the nycthemere. The gray rectangles show the range of time in which sunrise or sunset occurs

data (pseudo- $R^{2}=0.41$ ). Foraging activity was best described as a quadratic function of both temperature (Fig. S1A) and humidity (Fig. S1B): activity increased for increasing values of temperature and humidity, reached a maximum around $25^{\circ} \mathrm{C}$ and $66 \% \mathrm{RH}$ and decreased thereafter.

The activity rhythm of the colonies was characterized by two peaks: one in the morning, beginning just after sunrise, between 07:00 and 08:00, and one in the evening, beginning before sunset, between 15:00 and 16:00, and extending until 04:00-05:00 of the next day (Fig. 2). The nocturnal peak of activity was always higher than the diurnal one. Overall, activity was more intense in the humid than in the dry season (Table 1, season effect), particularly in the morning. The daily variation in foraging activity was significantly different between the dry and humid seasons (Table 1: interaction $H_{\text {cos }}$ : season). During the dry season, activity ceased almost completely between 10:00 and 16:00, while during the humid season, it was maintained, albeit at a low level, throughout the entire diurnal part of the nycthemere (Fig. 2). Activity raised again at the end of the afternoon but earlier in the humid season than in the dry season. It also carried on for a longer period of time into the night in the humid season than in the dry season.

Foraging efficiency differed between the two studied nests and depended significantly on season, time of day, air temperature, and humidity (Table 2 ; pseudo- $R^{2}=0.225$ ). It was significantly higher for Nest $1(37 \%)$ than for Nest 2 (29\%) and significantly higher in the humid than in the dry season: on average, $24 \%$ of the ants returning to the nest carried a leaf fragment in the dry season, while this percentage reached $38 \%$ in the humid season. Foraging efficiency started to increase at the beginning of the evening peak of activity and reached its higher level at the end of the night (Fig. S2A). Independent of the time of day foraging efficiency increased with both increasing temperature (Fig. S2B) and humidity (Fig. S2C).

\section{Collected biomass assessment}

The statistical model based on the time of day, temperature and humidity, fitted reasonably well the data on the number of ants returning with a leaf fragment for Nest 1 (pseudo$R^{2}=0.49$ ) but less so for Nest 2 (pseudo- $R^{2}=0.31$ ). The estimates of the models are indicated in Table 3. Over the period extending from November 10, 2011 to October 31, 2012 , the model yielded an estimated amount of dry biomass collected of $25.16 \mathrm{~kg}\left(\mathrm{CI}_{0.95} 17.11-37.78\right)$ for Nest 1 and $11.69 \mathrm{~kg}\left(\mathrm{CI}_{0.95} 6.94-20.23\right)$ for Nest 2 . The amount of vegetation collected varied differently between the two
Fig. 2 Mean daily variation (observation and model) of the average number of ants observed per minute on a foraging trail for a Nest 1 and $\mathbf{b}$ Nest 2, for each hour of the day. The bar on the upper part of the graphic shows the time corresponding to the diurnal part (white rectangle) and the nocturnal part (black rectangle) of the nycthemere. The gray rectangles show the range of time in which sunrise or sunset occurs

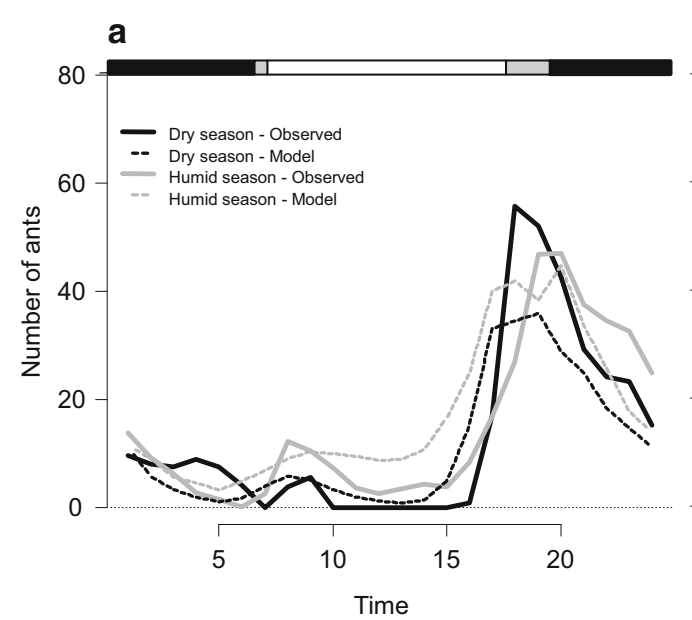

b

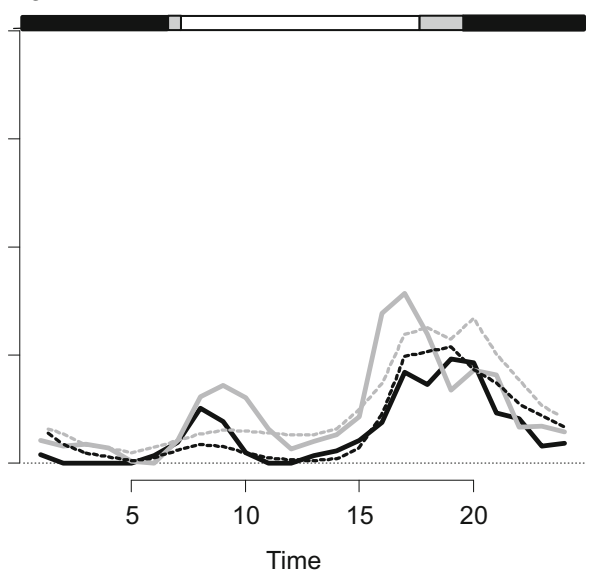


Table 1 Results of a statistical model to test for the influence of time of day, air temperature, humidity, season (dry/humid), and nest on the foraging activity of Atta capiguara

\begin{tabular}{lllrr}
\hline Effect & $d f$ & Resid. $d f$ & \multicolumn{1}{l}{$F^{\mathrm{a}}$} & \multicolumn{1}{l}{$P$} \\
\hline$H_{\text {cos }}^{\mathrm{b}}$ & 1 & 958 & 29.811 & $<\mathbf{0 . 0 0 1}$ \\
$H_{\text {sin }}^{\mathrm{b}}$ & 1 & 957 & 98.598 & $<\mathbf{0 . 0 0 1}$ \\
Temperature & 1 & 956 & 6.202 & $\mathbf{0 . 0 1 3}$ \\
Humidity & 1 & 955 & 0.153 & 0.696 \\
Season & 1 & 954 & 3.213 & 0.073 \\
Nest & 1 & 953 & 15.786 & $<\mathbf{0 . 0 0 1}$ \\
Temperature & 1 & 952 & 95.418 & $<\mathbf{0 . 0 0 1}$ \\
Humidity $^{2}$ & 1 & 951 & 7.942 & $\mathbf{0 . 0 0 5}$ \\
$H_{\text {cos }}$ : season & 1 & 950 & 5.398 & $\mathbf{0 . 0 2 0}$ \\
$H_{\text {sin }}$ : season & 1 & 949 & 0.588 & 0.443 \\
\hline
\end{tabular}

${ }^{a}$ GLM (family: quasi-Poisson; link: log; response: number of ants). Terms were added sequentially

b $H_{\text {sin }}$ and $H_{\text {cos }}$ are two auxiliary variables that are used to model the circadian rhythm (see "Materials and methods")

Bold values indicate probability below the significance threshold of 0.05

Table 2 Results of a statistical model to test for the influence of time of day, air temperature, humidity, season (dry/humid), and nest on the foraging efficiency of Atta capiguara, i.e., on the proportion of ants returning to the nest with a load

\begin{tabular}{lllcc}
\hline Effect & $d f$ & Resid. $d f$ & $F^{\mathrm{a}}$ & $P$ \\
\hline$H_{\text {cos }}^{\mathrm{b}}$ & 1 & 382 & 0.027 & 0.69 \\
$H_{\text {sin }}^{\mathrm{b}}$ & 1 & 381 & 20.411 & $<\mathbf{0 . 0 0 1}$ \\
Temperature & 1 & 380 & 19.957 & $<\mathbf{0 . 0 0 1}$ \\
Humidity & 1 & 379 & 37.627 & $<\mathbf{0 . 0 0 1}$ \\
Season & 1 & 378 & 15.619 & $<\mathbf{0 . 0 0 1}$ \\
Nest & 1 & 377 & 19.470 & $<\mathbf{0 . 0 0 1}$
\end{tabular}

a GLM (family: quasi-binomial; link: logit; response: proportion of ants returning to the nest with a load). Terms were added sequentially

${ }^{\text {b }} H_{\text {sin }}$ and $H_{\text {cos }}$ are two auxiliary variables that are used to model the circadian rhythm (see "Materials and methods")

Bold values indicate probability below the significance threshold of 0.05 nests (Fig. 3). It reached a minimal value in May for Nest 1 and in June for Nest 2, and a maximal value in September for Nest 1 and in March for Nest 2. The decrease in the amount of vegetation collected for Nest 2 may be due to the fact that for this nest, the number of active trails decreased during the dry season, while it increased for Nest 1 (Fig. S3: mean number of active trails in the humid season: 4.91 and 4.06, in the dry season: 10.47 and 3.44, for Nest 1 and Nest 2 , respectively).

\section{Discussion}

This study shows that A. capiguara can forage both during the day and the night in both the dry and humid seasons. Foraging activity was significantly correlated with the time of day and was characterized by two peaks of activity: one small peak at the beginning of the diurnal part of the nycthemere, and another one, much higher, at the end of the diurnal part of the nycthemere. Foraging efficiency, i.e., the proportion of ants returning to the nest with a load, varied along the 24-h cycle. It reached its lowest level at the end of the afternoon, when the traffic on the trails was mostly outbound, and its highest level at the end of the night, when the traffic was mostly nestbound.

Overall, we found that the traffic on foraging trails and the foraging efficiency were higher during the humid season than during the dry season. This can probably be explained by the higher availability of resource during the humid season, and by the fact that at this time of the year, the vegetation is formed by young leaves, which are preferred by LCA (Rockwood 1975; Shepherd 1985), because they are richer in nutrients and contain a smaller concentration of repellent or toxic secondary compounds (Hubbell et al. 1984). During the humid season, the morning peak of activity was higher, the activity began to rise earlier in the

Table 3 Results of a statistical model to test for the influence of time of day, air temperature, humidity, and season (dry/humid) on the number of ants returning to the nest loaded with a vegetation fragment for the two Atta capiguara nests studied

\begin{tabular}{|c|c|c|c|c|c|c|c|c|}
\hline & \multicolumn{4}{|l|}{ Nest 1} & \multicolumn{4}{|l|}{ Nest 2} \\
\hline & Estimate & SE & $t^{\mathrm{a}}$ & $P$ & Estimate & SE & $t^{\mathrm{a}}$ & $P$ \\
\hline Intercept & 4.140 & 0.163 & 25.309 & $<0.001$ & 3.730 & 0.169 & 22.076 & $<0.001$ \\
\hline$H_{\mathrm{cos}}^{\mathrm{b}}$ & 1.174 & 0.155 & 7.583 & $<0.001$ & 0.900 & 0.250 & 3.606 & $<0.001$ \\
\hline$H_{\mathrm{sin}}^{\mathrm{b}}$ & -0.419 & 0.102 & -4.120 & $<0.001$ & -0.333 & 0.157 & -2.117 & 0.035 \\
\hline Temperature & 1.568 & 0.207 & 7.576 & $<0.001$ & 1.375 & 0.238 & 5.770 & $<0.001$ \\
\hline Humidity & 0.136 & 0.041 & 3.305 & 0.001 & 0.067 & 0.039 & 1.735 & 0.083 \\
\hline Temperature $^{2}$ & -0.035 & 0.005 & -7.007 & $<0.001$ & -0.023 & 0.005 & -5.053 & $<0.001$ \\
\hline Humidity $^{2}$ & -0.001 & 0.000 & -3.309 & 0.001 & 0.000 & 0.000 & -1.267 & 0.206 \\
\hline
\end{tabular}

a GLM (family: quasi-Poisson; link: log; response: number of ants)

b $H_{\text {sin }}$ and $H_{\text {cos }}$ are two auxiliary variables that are used to model the circadian rhythm (see "Materials and methods")

Bold values indicate probability below the significance threshold of 0.05 


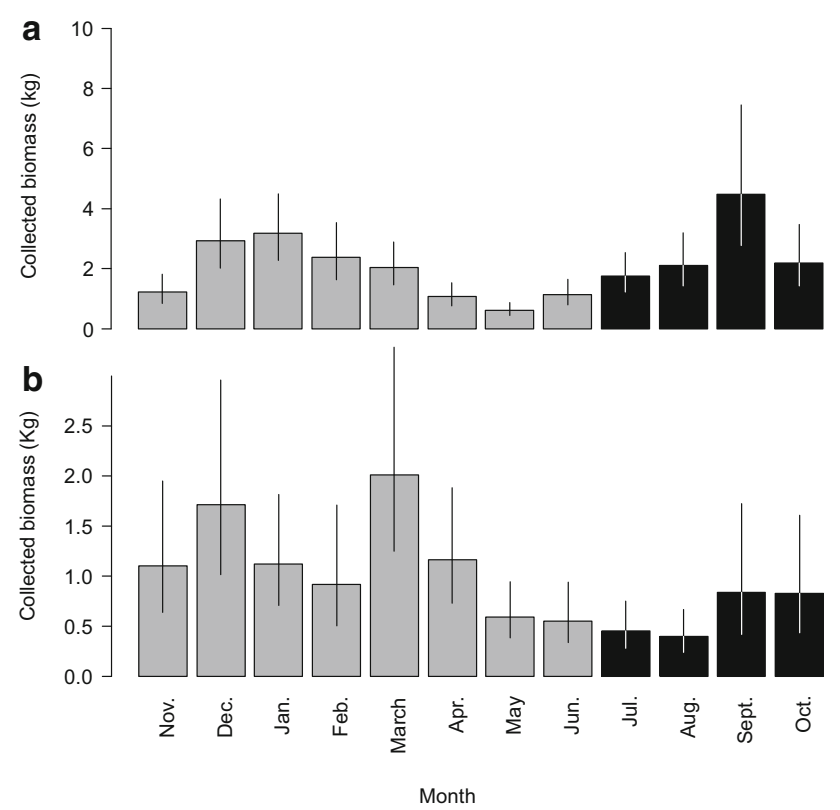

Fig. 3 Annual pattern of estimated dry biomass consumption for a Nest 1 and b Nest 2 between November 10, 2011 and October 31, 2012. The height of the bars corresponds to the predictions, the variation to $\pm \mathrm{CI}_{0.95}$

late afternoon, and was more extended throughout the night than during the dry season. This concord with the observations of Amante (1967b) who reported that during the humid season, foraging activity begins around 16:00 and ceases around 9:00 of the next day. The same author also noted that during the dry season, foraging activity was continuous between 08:00 and 18:00. This could sometimes happen in our survey, but most of the times we found that the activity ceased completely during the warmest hours of the day. Garcia (1997) in A. sexdens rubropilosa and Araujo et al. (2004) in A. bisphaerica also noted a decline or a cessation of foraging activity in the warmest period of the day during the dry season and, at least for A. sexdens rubropilosa, a concomitant increase in excavation activity.

We found a significant correlation between the level of activity of A. capiguara and air temperature. The level of activity reached its highest value when air temperature was close to $25{ }^{\circ} \mathrm{C}$, which corresponds to the lower limit of the range of temperatures for which Amante (1972) observed maximum activity $\left(25-30{ }^{\circ} \mathrm{C}\right)$. LCA are known to show plasticity in their heat tolerance (Angilletta et al. 2007), and the discrepancy between our data and those of Amante (1972) may be explained by differences in the average annual temperature of the environment in which the nests studied were located. Activity level was almost inexistent above $35{ }^{\circ} \mathrm{C}$ and below $15{ }^{\circ} \mathrm{C}$. The minimum thermal limit of activity we observed for A. capiguara is thus a few degrees above that reported for A. mexicana in Northern Mexico $\left(12{ }^{\circ} \mathrm{C}\right.$ : Mintzer 1979$)$ and for A. sexdens in subtropical Paraguay $\left(10^{\circ} \mathrm{C}\right.$ : Fowler and Robinson 1979). We found that, in addition to temperature, relative humidity had, albeit to a lesser extent than temperature, also a significant effect on the activity level of A. capiguara. Foraging activity reached its highest level around $66 \% \mathrm{RH}$. Temperature and relative humidity can be combined to calculate the water vapor pressure deficit (VPD), which is the difference between the actual water vapor pressure in the air and the saturation water vapor pressure at a given temperature. It gives a direct indication of the atmospheric moisture conditions independently of the temperature. It can be calculated with the formula given by Buck (1981). If ants avoid high VPD values, it could mean that they avoid desiccation as much as high temperatures. Fig. S4 shows that it is indeed the case: foraging activity decreases abruptly for water vapor pressure deficit above $2 \mathrm{kPa}$, which rarely occurs during the humid season (Fig. S5) and which corresponds to the time of minimum activity during the dry season (Fig. 2).

During the peak of the humid season, in January and February, the traffic on foraging trails decreased, but nonetheless was uninterrupted when a light rain was falling. However, it ceased completely in case of heavy rain. Hodgson (1955) did the same observation on A. cephalotes colonies inhabiting a tropical forest. Although the activity pattern of A. capiguara was significantly explained by both the daily and seasonal variation of air temperature and relative humidity, it is likely that the variation in other external factors, such as the level of ambient light (Hodgson 1955; Narendra et al. 2010; Amor et al. 2011), or internal factors, such as the nutritional requirements of the colony, influence the level of activity of this species. Finally, the existence of an endogen activity rhythm, independent of the factors mentioned above, cannot be totally excluded. As occurs for other species of ants (North 1993), LCA could be able to maintain a rhythm in constant conditions, and this rhythm could be entrained by the daily variation of temperature and humidity in natural conditions. Further experiments are required to test this hypothesis.

Based on the statistical model that was used to adjust the daily and seasonal variation of the number of ants returning to their nests with a leaf fragment, we estimated that the total dry biomass of vegetation collected over 1 year by the two nests studied amounted to $36.85 \mathrm{~kg}$, with a lower estimate of $24.05 \mathrm{~kg}$ and an upper estimate of $58.01 \mathrm{~kg}$. Given the fact that the percentage of water in the grass amounted to $74 \%$, this translates into an annual collection of $152.08 \mathrm{~kg}$ of fresh vegetation biomass (lower estimate: $100.21 \mathrm{~kg}$; upper estimate: $241.00 \mathrm{~kg}$ ). The amount of biomass collected by Nest 1 was more than doubled compared with Nest 2. This can be explained by both a smaller size of Nest 2 compared with nest 1 and by the fact that Nest 1 showed an increase in the number of active foraging trails during the 
dry season, whereas Nest 2 showed a decrease. These estimates are much lower than those calculated by Fowler et al. (1986) (110.2 and $78.5 \mathrm{~kg} /$ year/colony, respectively) based on activity census and closer to the estimates calculated by Fowler et al. (1990) (33.2 kg/year/colony) with the conversion method, i.e., a calculation based on the ratio of fresh fungal to dead fungal substrate. Comparisons between these estimates, however, are difficult and should be considered with a lot of caution, since the biomass collected annually is bound to depend on a variety of factors, e.g., the size of the nests studied, the local meteorological conditions, the presence of grazing cattle or the species of grass collected.

Because of the huge size of their nests and their intense activities, LCA are considered as the dominant herbivores in neotropical ecosystems in which they act as ecosystem engineers (Meyer et al. 2011). Although a lot of scientists have investigated the impact of LCA on the vegetation of primary (Wirth et al. 2003) and secondary (Silva et al. 2012) tropical forests, a few studies have focused on the ecological role of the LCA species found in tropical savannahs or artificial pastures. This study is one of the first to make a reliable assessment of the annual herbivory rate of LCA in cultivated pastures. It also provides data that could help to improve integrated pest management solutions. In this study, we showed, for example, that $A$. capiguara is more active at night, when the temperature lies in the range of $20-30{ }^{\circ} \mathrm{C}$ and the relative humidity lies in the range of $50-70 \%$. If this information was used to place poison baits on foraging trails, one could ensure that more baits are retrieved to the nest, and thus, that less toxic substances are dispersed in the environment. Finally, as temperature is one of the main drivers of ant distribution (Jenkins et al. 2011), a better knowledge of the thermal preferences expressed by these ants can also provide essential data to develop species distribution models and build realistic scenarios on the distributional shift and changes in levels of abundance (Ehrlen and Morris 2015) of these economically important species in a time of climate change.

Acknowledgments Financial support and stipends were given to NC by the Fundação de Amparo à Pesquisa do Estado de São Paulo (FAPESP) (2011/003699). During her stay in BotucatuVF was financed by a CAPES-COFECUB grant (633/08) and SB was financed by a grant of the French Ministry of Education. We thank L. van Oudenhove for critically reading an earlier version of the MS and for fruitful discussions and advice to improve the MS.

\section{References}

Amante E (1967a) A formiga saúva Atta capiguara, praga das pastagens. O Biológico 33:113-120 (São Paulo)

Amante E (1967b) Saúva tira boi da pastagem. Coopercotia 23:38-40
Amante E (1972) Influência de alguns fatores microclimáticos sobre a formiga saúva Atta laevigata F. Smith, 1858, Atta sexdens rubropilosa Forel, 1908, Atta bisphaerica Forel, 1908 e Atta capiguara Gonçalves, 1944 (Hymenoptera, Formicidae), em formigueiros localizados no estado de São Paulo. PhD Dissertation-Escola Superior de Agricultura "Luiz de Queiroz", Universidade de São Paulo, Piracicaba

Amor F, Patrocinio O, Cerdá X, Boulay R (2011) Solar elevation triggers foraging activity in a thermophilic ant. Ethology 117:1031-1039

Angilletta MJ, Wilson RS, Niehaus AC, Sears MW, Navas CA, Ribeiro PL (2007) Urban physiology: city ants possess high heat tolerance. PLoS One 2:e258

Araujo MS, Della Lucia TMC, Coutinho M (2004) Impacto da queima da palhada de cana-de-açucar no ritmo diario de forrageamento de Atta bisphaerica Forel (Hymenoptera, Formicidae). Rev Bras Zool 21:33-38

Buck AL (1981) New equations for computing vapor pressure and enhancement factor. J Appl Meteor. 20:1527-1532

Cedenõ-Leon A (1984) Los bachacos: aspectos de su ecologia. Fondo Editorial, Venezuela

Costa AN, Vasconcelos HL, Vieira-Neto EHM, Bruna EM (2008) Do herbivores exert top-down effects in Neotropical savannas? Estimates of biomass consumption by leaf-cutter ants. J Veg Sci 19:849-854

Delabie J, Alves HSR, Reuss-Strenzel GM, do Carmo AFR, do Nascimento IC (2011) Distribuição das formigas-cortadeiras dos gênerosAcromyrmex e Atta no novo mundo. In: Della Lucia TMC (ed) Formigas cortadeiras-da bioecologia ao manejo, Universidade Federal de Viçosa, pp 80-101

Della Lucia TMC, Gandra LC, Guedes RNC (2014) Managing leafcutting ants: peculiarities, trends and challenges. Pest Manag Sci 70:14-23

Ehrlen J, Morris WF (2015) Predicting changes in the distribution and abundance of species under environmental change. Ecol Lett $18: 303-314$

Farji-Brener AG (1993) Influencia de la estacionalidad sobre los ritmos forrageros de Atta laevigata (Hymenoptera: Formicidae) em uma sabana tropical. Rev Biol Trop San José 41:897-899

Forti LC, Boaretto MAC (1997) Formigas cortadeiras: biologia, ecologia, danos e controle. Departamento de Defesa Fitossanitária, Universidade Estadual Paulista, Botucatu

Fowler HG, Robinson SW (1979) Foraging by Atta sexdens: seasonal patterns, caste and efficiency. Econ Entomol 4:239-247

Fowler HG, Forti LC, Pereira V, Saes NB (1986) Economics of grasscutting ants. In: Lofgren CS, Vander Meer RK (eds) Fire ants and leaf-cutting ants. Biology and management. Westview Press, Boulder, pp 18-35

Fowler HG, Forti LC, Romagnano LFT (1990) Methods for the evaluation of leaf-cutting ants harvest. In: Vander Meer RK, Jaffé K, Cedena A (eds) Applied myrmecology—a world perspective. Westview Press, Boulder, pp 228-241

Garcia IP (1997) Atividade forrageira da saúva Atta sexdens L., 1758 (Hymenoptera: Formicidae) em Eucalyptus grandis Hill ex Maiden e em mata secundária.Botucatu. PhD Dissertation, Faculdade de Ciências Agronômicas de Botucatu, Universidade Estadual Paulista

Herz H, Beyschlag W, Hölldobler B (2007) Herbivory rate of leafcutting ants in a tropical moist forest in Panama at the population and ecosystem scales. Biotropica 39:482-488

Hodgson ES (1955) An ecological study of the behavior of the leafcutting ant Atta cephalotes. Ecology 36:293-304

Hölldobler B, Wilson EO (1990) The ants. Harvard University Press, Cambridge

Hölldobler B, Wilson EO (2010) The leaf-cutting ants: civilization by instinct. W.W. Norton \& Company, New York, London 
Hubbell SP, Howard JJ, Wiemer DF (1984) Chemical leaf repellency to an Attine ant: seasonal distribution among potential host plant species. Ecology 65:1067-1076

Jenkins CN, Sanders NJ, Andersen AN, Arnan X, Brühl CA, Cerdá X, Ellison AM, Fisher BL, Fitzpatrick MC, Gotelli NJ, Gove AD, Guénard B, Lattke JE, Lessard J-P, McGlynn TP, Menke SB, Parr CL, Philpott SM, Vasconcelos HL, Weiser MD, Dunn RR (2011) Global diversity in light of climate change: the case of ants. Diversity Distrib 17:652-662

Lewis T, Pollard GV, Dibley GC (1974a) Rhythmic foraging in the leaf-cutting ant Atta cephalotes (L.) (Formicidae: Attini). J Anim Ecol 43:129-141

Lewis T, Pollard GV, Dibley GC (1974b) Micro-environmental factors affecting diel patterns of foraging in the leaf-cutting ant Atta cephalotes (L.) (Formicidae: Attini). J Anim Ecol 43:143-154

Lugo AE, Farnworth EG, Pool D, Jerez P, Kaufman G (1973) The impact of the leaf cutter ant Atta colombica on the energy flow of a tropical west forest. Ecology 54:1292-1301

Meyer ST, Leal IR, Tabarelli M, Wirth R (2011) Ecosystem engineering by leaf-cutting ants: nests of Atta cephalotes drastically alter forest structure and microclimate. Ecol Entomol 36:14-24

Mintzer A (1979) Foraging activity of the Mexican leaf-cutting ant Atta mexicana in a Sonooran desert habitat. Insect Soc 26:364-372

Narendra A, Reid SF, Hemmi JM (2010) The twilight zone: ambient light levels trigger activity in primitive ants. Proc R Soc B Biol Sci 277:1531-1538

North RD (1993) Entrainment of the circadian rhythm of locomotor activity in wood ants by temperature. Anim Behav 45:393-397
Pearce-Duvet JMC, Elemans CPH, Feener DH (2011) Walking the line: search behavior and foraging success in ant species. Behav Ecol 22:501-509

Rockwood LL (1975) The effects of seasonality on foraging of two species of leaf-cutting ants (Atta) in Guanacaste Province, Costa Rica. Biotropica 7:176-193

R Development Core Team (2011) R: a language and environment for statistical computing. R Foundation for Statistical Computing, Vienna.http://www.R-project.org/

Sheperd JD (1985) Adjusting foraging effort to resources in adjacent colonies of the leaf-cutter ant, Atta colombica. Biotropica 17:245-252

Silva PSD, Leal IR, Wirth R, Melo FPL, Tabarelli M (2012) Leafcutting ants alter seedling assemblages across second-growth stands of Brazilian Atlantic forest. J Trop Ecol 28:361-368

van Oudenhove L, Billoir E, Boulay R, Bernstein C, Cerdá X (2011) Temperature limits trail following behaviour through pheromone decay in ants. Naturwissenschaften 98:1009-1017

Wetterer JK (1990) Diel changes in forager size, activity, and load selectivity in a tropical leaf- cutting ant Atta cephalotes. Ecol Entomol 15:97-104

Wirth R, Herz H, Ryel RJ, Beyschlag W, Hölldobler B (2003) Herbivory of leaf-cutting ants-a case study on Atta colombica in the tropical rainforest of Panama. Springer, Berlin, Heidelberg

Zuur AF, Ieno EN, Walker NJ, Saveliev AA, Smith GM (2009) Mixed effects models and extensions in ecology with R. Springer, New York 